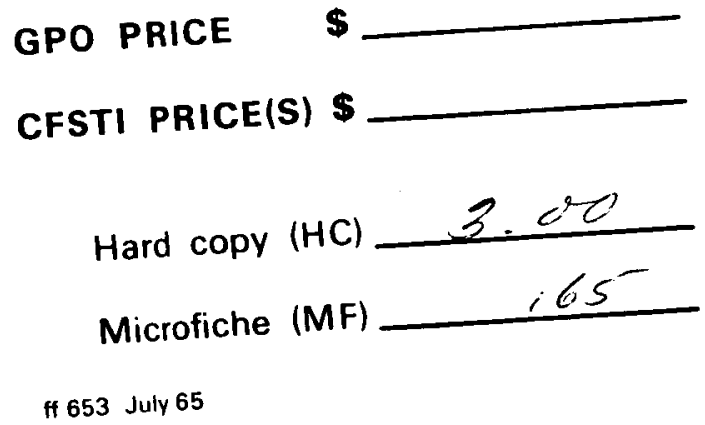

THE ANALYSIS OF TURBULENCE FROM DATA OBTAINED WITH A LASER VELOCIMETER

By N. E. Welch and W. J. Tomme

Propulsion and Vehicle Engineering Laboratory

NASA

George C. Marshall

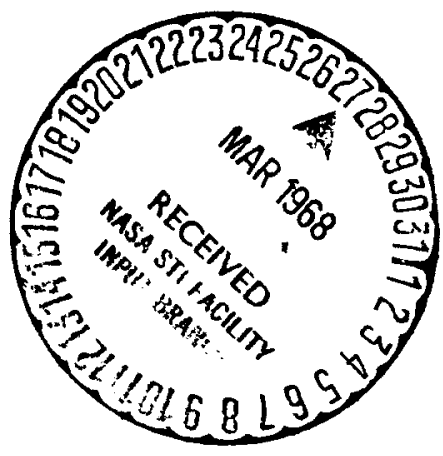

Space Flight Center,

Huntsville, Alabama
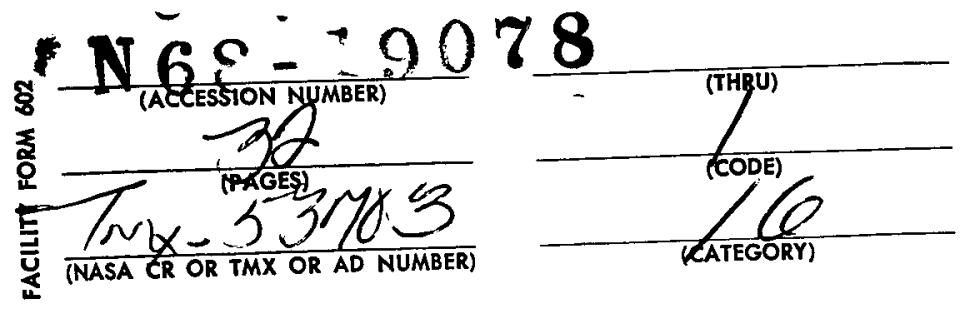
TECHNICAL MEMORANDUM X-53703

\title{
THE ANALYSIS OF TURBULENCE FROM DATA \\ OBTAINED WITH A LASER VELOCIMETER
}

By

N. E. Welch and W. J. Tomme

George C. Marshall Space Flight Center

Huntsville, Alabama

\begin{abstract}
This investigation concerned the use of a laser velocimeter to determine point velocities in a turbulent liquid flowing in a pipe. The velocity distribution was determined at each point and for each rate of bulk flow. This method of measurement affords data unaffected by any proturberance into the flow stream. The frequency response of the base instrument and electronics is sufficient to measure all frequencies of turbulence investigated.
\end{abstract}

The data was verified by comparing the mean velocity profile calculated from the probability distribution function with profiles determined by other methods of mean velocity measurement. The variance of the distribution function was verified with turbulent diffusion data.

The velocity distribution function, as derived from statistical reasoning, was found to properly describe the measured axial velocity components.

The change in the variance of the velocity distribution function is derived and is compared with the measured variance.

NASA - GEORGE C. MARSHALL SPACE FLIGHT CENTER 
NASA-GEORGE C. MARSHALL SPACE FLIGHT CENTER

TECHNICAL MEMORANDUM X-53703

THE ANALYSIS OF TURBULENCE FROM DATA OBTAINED WITH A LASER VELOCIMETER

\title{
By
}

N. E. Welch and W. J. Tomme

\author{
APPLIED RESEARCH BRANCH \\ PROPULSION DIVISION \\ PROPULSION AND VEHICLE ENGINEERING LABORATORY \\ RESEARCH AND DEVELOPMENT OPERATIONS
}




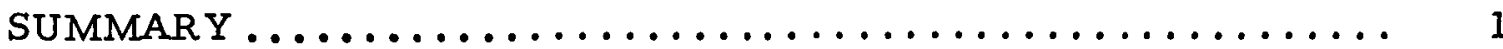

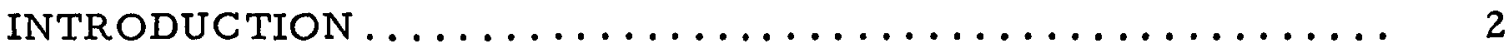

DESCRIPTION OF EQUIPMENT .................. 2

The Optical System ...................... 2

The Electronic System ....................... 3

PRESENTATION OF THE DATA.................. 4

PROCESSING OF THE DATA.................. 5

ANALYSIS OF THE DATA ...................... 6

Derivation of the Velocity Distribution Function.......... 6

Derivation of the Relationship Between Standard

Deviation $(\sigma)$ and Radius $(r) \ldots \ldots \ldots \ldots \ldots \ldots \ldots, 8 \ldots \ldots \ldots$

Check Against Turbulent Diffusion Data ............. 11

CONCLUSIONS ........................... 14

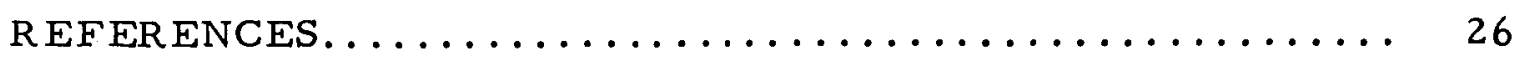


Optical System ..................... 15

Electronic System .................... 16

Centerline Velocity Distribution $(R e=4605) \ldots \ldots .17$

Centerline Velocity Distribution ( $R e=7808)$.

Centerline Velocity Distribution $(R e=8510) \ldots \ldots \ldots 18$

Centerline Velocity Distribution (Re $=9310) \ldots \ldots \ldots 18$

Standard Deviation for Various Reynolds Number s.. 19

Standard Deviation at Several Radii (Re $=8510$ ).... 20

Velocity Distribution at an $r / R$ of 0.243 and a Reynolds Number of 8510

Velocity Distribution at an $r / R$ of 0.405 and a

Reynolds Number of 8510 .

Velocity Distribution at an $\mathrm{r} / \mathrm{R}$ of 0.566 and

Velocity Distribution at an $r / R$ of 0.729 and a

Reynolds Number of $8510 \ldots \ldots \ldots \ldots \ldots \ldots \ldots$

Velocity Distribution at an $r / R$ of 0.825 and a

Reynolds Number of $8510 \ldots \ldots \ldots \ldots \ldots \ldots . \ldots 23$

15

Effect of Sampling Period

Diffusion Characteristics of Turbulent Field.

\section{LIST OF TABLES}

Table
Title

Page

Average Values of Variance and Velocity at

Centerline 25 


\title{
THE ANALYSIS OF TURBULENCE FROM DATA \\ OBTAINED WITH A LASER VELOCIMETER
}

\section{By}

\author{
N. E. Welch and W. J. Tomme* \\ George C. Mar shall Space Flight Center
}

SUMMARY

The Laser Velocimeter was utilized to obtain sampled velocity data in turbulent flow in a cylindrical pipe section without interrupting the flow field. The velocity distribution function was measured at several radii for Reynolds numbers between 4000 and 9500 . The mean velocity and variance were calculated from each distribution function. The mean velocities were then plotted versus dimensionless radius and compared to Nikuradse's correlation. The experimental and calculated values agree within the expected error of measurement of the bulk flow rate. The intensity of turbulence was also calculated from the measured distribution functions and was found to be approximately 10 percent higher than values measured with Hot Wire Anemometers. This difference could be the result of white noise in the signal rather than more accurate measurements. The longitudinal turbulent diffusion characteristics of the flow field were also calculated from the velocity distribution function and compared with published eddy diffusivity data. However, errors due to assumptions in the calculations and errors in the published data allowed comparison of only gross effects.

A mathematical expression of the velocity distribution function was derived on a statistical basis. An expression for the variation of the distribution function with radius was also derived. Both expressions were found to agree with the data.

* Brown Engineering Company, Technical Support Contractor. 


\section{INTRODUCTION}

The various techniques used to measure the velocity of liquids in turbulent flow have traditionally involved the use of some device protruding into the flow stream. Most devices of this type also suffer from sufficient frequency response; hence, turbulent measurements were difficult. In this investigation, a beam of light is used to measure velocity through application of the doppler effect. Further, an electronic system was developed that enables the measurement of the velocity distribution at a point and with frequency response believed to be well above that required.

The purpose of this investigation is to define the velocity distributions for liquids in turbulent flow for various Reynolds numbers and at several radial positions in the pipe. The velocity distributions were measured, and from them, the mean and the variance were established. In addition, the distributions obtained are illustrated revealing the skewness as affected by the radial position in the pipe. The results obtained provide information on turbulent liquid flow that was not previously available.

Previous investigator $s$ have used eddy diffusion data to determine inferences concerning the velocity distribution. Foreman, Lewis, and George (Reference 1) described the technique for using the laser for doppler measurement in fluids.

\section{DESCRIPTION OF EQUIPMENT}

The velocimeter system is composed of three separate elements. A liquid flow loop provided a constant bulk flow through a glass tube of $2.2 \mathrm{~cm}$ inside diameter. Since the flow system is standard, it is not described herein. A gas laser is used with associated optical equipment and is referred to as the optical system. The third part of the system is the electronics, which converts the optical measurement into a useable electronic signal.

The Optical System

An $\mathrm{H}_{e}-\mathrm{N}_{e}$ gas laser was used to provide a beam of coherent light that was directed through the glass tube as shown in Figure 1. The focal point was located at six different positions throughout the course of the 
investigation. Light is scattered from the focal point by small particles in the water. A lens arranged at a known angle was to receive the light scattered at that angle. This light differs in frequency from the parent beam due to the doppler effect produced by the motion of the solids in the water. These two light beams, when recombined on the cathode of a photomultiplier, produce a heterodyne signal. For the studies described in this report, the heterodyne frequency was less than 500 $\mathrm{KH}_{\mathrm{z}}$. The optical system was mounted on a moveable bed separate from the glass tube. This feature enabled the traverse of the fluid within the pipe. The optical arrangement was used to measure the longitudinal component of the velocity at the focal point. Concisely, the optical system provided a heterodyne signal that was directly proportional to the longitudinal component of the fluid velocity at the focal point.

The Electronic System

The photomultiplier shown in Figure 1 produces a small electrical signal which is the heterodyne of the two light beam frequencies. This signal varies both in amplitude and in frequency. The amplitude variations are caused by several factors including the size of the particles and their number and location in the scattering volume. The frequency variations are caused by the changes in liquid velocity. Noise is present on the signal; a signal-to-noise ratio of one was typical. The amplitude of the heterodyne varied by as much as $40 \mathrm{db}$ resulting in a highly discontinuous signal. Under these conditions, the use of a system making a continuous measurement of frequency was subject to much doubt, so the system shown in Figure 2 was developed. This system measures the frequency distribution function directly by scanning across the mean frequency. The relative rate of occurrence of frequencies is then determined, and a form of autocorrelation is established.

The signal from the photomultiplier is first amplified and filtered to remove all of the high frequency noise, including some radio frequency from the laser. A trigger level is set so that noise alone would not trigger the system. When the positive half of the heterodyne wave triggers the system, the "data one-shot" produces a very short rectangular pulse. At the same time, two other one-shots are energized. These are the "sample delay" and the "timing" one-shots. The latter two are much longer in duration than the data pulse. The sample delay one-shot stays energized for three and one-half time constants of the heterodyne frequency. Its purpose is to prevent re-trigger of the timing one-shot until the arrival of the fourth data pulse or a later one. When the timing one-shot turns off, it simultaneously energized the sample pulse. If this pulse is coincident with a data pulse, the "and-gate" commands an event pulse which 
is of fixed duration. The integration of these pulses would then determine a relative rate of occurrence at the time period dictated by the timing one-shot. In normal operation, this timing one-shot was swept continuously and linearly with time from one-half the period of the heterodyne frequency to three and one-half periods. The analog voltage of the integrated event pulse was converted to digital records for entry to a digital computer.

Another integrator develops an analog voltage proportional to the average data rate, and this is also digitized. Compensation is made for any variations in the data rate, because this has a proportional effect on the output of the other integrator. Normally, the data rate was constant within five percent over the course of a $r$ un.

\section{PRESENTATION OF THE DATA}

Velocity distributions were obtained at the center line of the tube for four Reynold's numbers, and velocity profile measurements were made at five radii. Figures 3 through 6 show typical velocity distributions obtained at Reynold's numbers of 4605, 7808, 8510, and 9310 . Since the velocity is directly proportional to the heterodyne frequency, the velocity distribution functions were derived directly from the heterodyne frequency distributions. Table I shows the results of five series of $r$ uns with as many as eight $r$ uns per series. The values for $\sigma^{2}$, the variance, and $\bar{v}$, the mean velocity, are average values compiled over all runs. The average bulk velocity, $\mathrm{V}$, is also shown. Using Nikuradse's data (2), the center stream velocity to bulk average velocity ratios differed over all series by an average error of less than 1 percent.

The variation of the standard deviation with Reynolds number is shown in Figure 7. Some of this increase in $\sigma$ is a result of the increase of center stream velocity. This effect is linear by nature. Also indicated is an increase in turbulence with $R_{e}$ as would be expected.

Figure 8 shows a velocity profile obtained by plotting the mean velocities obtained at several radii within the pipe. The continuous curve represents Nikuradse's data and in general there is very close agreement. Measurements closer to the wall are possible but were inconvenient due to the changes required; hence, they were not attempted during this investigation.

Figure 9 illustrates the variation of the standard deviation with radius for a Reynolds number of 8510 . Indications are that a maximum 
is obtained in the vicinity of $r / R$ ratio of 0.75 . Considering the shear created by the tube wall and the high center stream velocity, this maximum is in the region of maximum probability of eddy motion. The standard deviation as a function of radius is discussed in detail in a later section.

The combined velocity distributions obtained at $r / R$ ratios of 0.243 , $0.405,0.566,0.729$, and 0.825 are shown in Figures 10 through 14 respectively. These measurements were made at a Reynolds number of 8510. The center stream distributions were all very nearly normal. A skewness appears and increases as $r$ approaches $R$. The mean velocity in all cases was equal or less than the most probable velocity.

The mean velocity and the variance were calculated by the standard definitions and are shown as equations (1) and (2).

$$
\begin{aligned}
\bar{v} & =\frac{\int g(v) v d v}{\int g(v) d v} \\
\sigma^{2} & =\frac{\int_{g}(v)(v-\bar{v})^{2} d v}{\int g(v) d v}
\end{aligned}
$$

\section{PROCESSING OF THE DATA}

The electronic system delivers a series of three distributions for each run. These represent the locations of the first, second and third heterodyne wave peaks following the beginning time as determined by the leading edge of the timing pulse. These three distributions are generated by turbulence and some noise. Since the noise is noncoherent, it is extracted statistically by assuming that the variance attributable to it is constant for all three distributions, while that for turbulence is not. This implies that turbulence is coherent over a period of three times the heterodyne period or approximately 20 micro seconds. A heterodyne frequency distribution is obtained that can then be directly converted to velocity by equation (3).

$$
v=K \cdot f
$$

For the optical arrangement used, the value of $K$ was $1.5 \times 10^{-4}$. 


\section{ANALYSIS OF THE DATA}

\section{Derivation of the Velocity Distribution Function}

The probability distribution function for the axial velocity component, as utilized herein, can be derived from random walk theory, or by using the same procedural reasoning as that incorporated in the derivation of the Maxwell - Boltzmann equation for molecular velocity distributions in gases. However, since turbulence is a macroscopic mechanism, and the axial velocity component is an incomplete measure of that mechanism, one must proceed with reserve and considerable experimental verification.

Choose a macroscopic spatial cell size $\Delta$, sufficiently large that the average molecular velocities are constant and equal for all cells, but sufficiently small that the large number theory is applicable to the turbulent region under consideration, and determine the distribution corresponding to a maximum likelihood of occurrence (canonical distribution). The following equation is obtained.

$$
\frac{N_{i}}{N}=\frac{g_{i} \operatorname{Exp}\left(-\lambda v_{i}^{2}\right)}{\sum g_{i} \operatorname{Exp}\left(-\lambda v_{i}^{2}\right)}
$$

Where

$$
\begin{aligned}
\mathrm{g}_{i}= & \text { a priori probability that a given cell will experience axial } \\
& \text { velocity } \mathrm{V}_{\mathrm{i}} . \\
\mathrm{N}_{\mathrm{i}}= & \text { number of cells of size } \Delta \text { with an axial velocity } \mathrm{v}_{\mathbf{i}} . \\
\mathrm{N}= & \text { total number of cells in flow field. } \\
\mathrm{v}_{\mathrm{i}}= & \mathrm{v}_{\mathrm{i}}-\mathrm{u} \\
\mathrm{v}_{\mathrm{i}}= & \text { instantaneous axial velocity. } \\
\mathrm{u}= & \text { mean axial velocity }
\end{aligned}
$$

If

$$
g_{i}=\phi\left(v_{i}\right) \Delta v_{i}
$$

then

$$
\frac{N_{i}}{N}=\frac{\phi\left(v_{i}\right) \operatorname{Exp}\left[-\lambda\left(v_{i}-u\right)^{2}\right] \Delta v_{i}}{\sum \phi\left(v_{i}\right) \operatorname{Exp}\left[-\lambda\left(v_{i}-u\right)^{2}\right] \Delta v_{i}}
$$


The continuous approximation is written as follows.

$$
f(v)=\frac{\phi(v) \operatorname{Exp}\left[-\lambda(v-u)^{2}\right]}{\int_{-\infty}^{+\infty} \phi(v) \operatorname{Exp}\left[-\lambda(v-u)^{2}\right] d v}
$$

Where $f(v)=\frac{d N}{N d v}$ and $f(v) d v$ is the probability that a cell will experience an axial velocity between $v$ and $v+d v$.

The nature of $\phi(v) d v$ can be rationalized from known mean velocity profiles and shear stress correlations. If no shear is present $\left(\tau_{r z}=0\right)$, there is no reason to believe that there is any velocity preference, so one can logically assume that $\phi(v) d v \alpha d v$. This, of course, is the condition at the center of the pipe $(r=0)$. Furthermore, since frictional losses are known to increase according to $\mathrm{v}^{\mathrm{x}}$, it can reasonably be as sumed that $\phi(v) \propto 1 / v^{x}$. However, the mean velocity profile correlation for $R_{e} \approx 10^{4}$ indicates that $x=(r / R)^{7}$ where $R$ is the radius of the pipe. This rationalization leads to the relation

$$
\phi(v) d v \propto \frac{d v}{v^{x}}
$$

Substituting equation (6) into equation (5) gives

$$
f(v)=\frac{\operatorname{Exp}\left[-\lambda(v-u)^{2}\right]}{v^{x} \int_{-\infty}^{+\infty} \operatorname{Exp}\left[-\lambda(v-u)^{2}\right] \frac{d v}{v x}}
$$

On the axis $(r=0)$, equation (7) reduces to

$$
f(v)=\frac{\operatorname{Exp}\left[-\lambda(v-u)^{2}\right]}{2 \int_{0}^{\infty} \operatorname{Exp}\left[-\lambda(v-u)^{2}\right] d v}
$$

If the indicated integration is performed and $\lambda$ is set equal to $1 / 2 \sigma^{2}$, the following equation is obtained. 


$$
f(v)=\frac{1}{\sigma \sqrt{\pi}} \operatorname{Exp}\left[-\frac{(v-u)^{2}}{2 \sigma^{2}}\right]
$$

From Figure 5, 10, and 11, it is readily seen that for small values of $r / R$ the distribution is normal.

From Figure 14 it is seen that as $r / R$ approaches 1 , the high velocity components become less probable than the low velocity components, as indicated by equation (7). Furthermore, $\phi(v)=1 / v^{x}$ produces the correct amount of skewness for $r / R=0.83$ (Figure 14), indicating that the rationalization leading to the $\phi(v) d v$ expression may have merit. However, there is not sufficient data available near the wall to fully verify the relationship at this time. In view of this, equation (8) was correlated with the data by correlating $\sigma$ with the radius and the Reynold's number for a radius ratio of $O \leqq r / R \leqq 0.825$ and a $R$ eynold's number of $R_{e} \leqq 10^{4}$. Verification of equation (7) and additional correlations of $\sigma$ will be obtained in the future.

\section{Derivation of the Relationship between Standard \\ Deviation $(\sigma)$ and Radius $(r)$}

The equation that describes the relationship between the standard deviation of the velocity distribution function and the radius is also derivable from statistical mechanical considerations. This is accomplished by determining the most probable distribution of eddies as a function of volume available per unit length of tube, that is, of volume available per unit length of tube that is compatible with two known physical restraints.

The canonical distribution in this case is determined to be

$$
\frac{n_{i}}{n}=\frac{g_{i} \operatorname{Exp}\left(-\beta V_{i}\right)}{\sum g_{i} \operatorname{Exp}\left(-\beta V_{i}\right)}
$$

where

$$
\begin{aligned}
n_{i}= & \text { number of eddies with volume } v_{i} . \\
v_{i}= & \text { volume of eddy group } i \text { expressed as a fraction of the total } \\
& \text { volume per unit length of pipe. }
\end{aligned}
$$


Let $g_{i}=4 \pi V_{i}^{2} d V_{i}$ that is, the a priori probability $g_{i}$ is equal to the fraction of the volume that lies between $V_{i}$ and $V_{i+1} \cdot$ Substituting into equation (9), and writing the continuous function approximation, the following equation is obtained

$$
P(V)=\frac{d n}{n d v}=\frac{\operatorname{Exp}(-\beta V)}{\int_{0}^{1} V^{2} \operatorname{Exp}(-\beta V) d V}
$$

Performing the indicated integration gives

$$
P(V)=A_{v}^{\prime} V^{2} \operatorname{Exp}(-\beta V)
$$

Where

$$
A_{v}^{\prime}=\frac{\beta^{3}}{2-\frac{\beta^{2}+2 \beta+2}{\operatorname{Exp}(\beta)}}
$$

The area under the velocity distribution function between $-(v-u)$ and $+(v-u)$ is the probability that the axial velocity will lie in this range and is equal to $k \sigma$. Since the axial velocity is a result of the eddy condition, $\mathrm{P}(\mathrm{V})$ should be proportional to $\sigma$; therefore

$$
P(V)=k \sigma
$$

and

$$
\sigma=A_{V} V^{2} \operatorname{Exp}(\beta V)
$$

where

$$
A_{v}=A_{v}^{\prime} / k
$$

The fluid is motionless at the pipe wall so $\sigma \rightarrow 0$ as $r \rightarrow R$. If as $r \rightarrow R$ the volume available for the formation of eddies approaches zero, the $\sigma$ relationship holds. As $r \rightarrow 0$, the shear stress approaches zero, and the fluid has a tendency to form streamlines. Therefore, $\sigma$ should approach a minimum as $\mathrm{r} \rightarrow 0(\mathrm{~V} \rightarrow 1)$, and 


$$
\sigma=\sigma_{0} \quad \text { at } \quad \mathrm{V}=1(\mathrm{r}=0)
$$

Substituting, gives

$$
\sigma_{0}=A_{v} \operatorname{Exp}(-\beta)
$$

Furthermore,

$$
\frac{\sigma}{\sigma_{0}}=\operatorname{Exp}(\beta) V^{2} \operatorname{Exp}(-\beta V)
$$

Since there is no reason to believe that anything other than volume, $\sigma_{\min }$ at $V=1$, and $\sigma=0$ at $V=0$ restrains the system, it is only reasonable to assume that $\sigma_{\max }$ occurs at $V=\frac{1}{2}$, so

$$
\begin{aligned}
\frac{d}{d v}\left(\frac{\sigma}{\sigma_{0}}\right) & =0 \\
& =\frac{1}{2} \operatorname{Exp}(\beta) \operatorname{Exp}\left(-\frac{\beta}{2}\right)\left(2-\frac{\beta}{2}\right)
\end{aligned}
$$

or $\beta=4$

Substituting $\beta=4$, gives

$$
\frac{\sigma}{\sigma_{0}}=\operatorname{Exp}(4) V^{2} \operatorname{Exp}(-4 V)
$$

However,

$$
V=\frac{R^{2}-r^{2}}{R^{2}}=1-\left(\frac{r}{R}\right)^{2}
$$

therefore,

$$
\frac{\sigma}{\sigma_{0}}=54.6\left[1-\left(\frac{\mathbf{r}}{R}\right)^{2}\right]^{2} \operatorname{Exp}\left\{-4\left[1-\left(\frac{r}{R}\right)^{2}\right]\right\}
$$

Figure 9 is a comparison of equation (12) and the experimental data. The solid line is calculated from equation (12) and each data point is an average standard deviation calculated from several measured distribution functions. 
Equation (12) agrees surprisingly well with the data. The calculated value of $\sigma / \sigma_{0}$ deviates from the data less than two percent in the worst case.

An insufficient amount of data is available at this time to correlate the standard deviation with Reynold's number. However, the four values of standard deviation on the axis $\left(\sigma_{0}\right)$ that have been obtained for Reynold's numbers from $4 \times 10^{3}$ to $0 \times 10^{3}$ are shown in Figure 7 . The variation of $\sigma$ with Reynold's number is approximately proportional to the Reynold's number to the 0.9 power. the pressure drop in this range is proportional to the velocity to the 1.7 power, so $\sigma_{0}^{2}$ is increasing approximately proportional to the pressure drop.

\section{Check Against Turbulent Diffusion Data}

According to Taylor's treatment

$$
\mathrm{D}=\frac{\overline{\mathrm{v}^{2}} \mathrm{~T}}{2}
$$

Where

$$
\begin{aligned}
& \mathrm{D}=\text { Eddy diffusivity } \\
& \overline{\mathrm{v}^{2}}=\text { Mean square velocity }
\end{aligned}
$$

and $T$ is a time interval sufficiently large that no correlation exists between $v(t)$ and $v(t+T)$.

Since $\overline{\sigma^{2}}=\overline{v^{2}}, \overline{v^{2}}$ can be obtained from equation (12).

$$
\overline{\sigma^{2}}=\frac{2}{R^{2}} \int_{0}^{R} r \quad \sigma^{2}(r) d r
$$

where

$$
\sigma^{2}=(54.6)^{2} \sigma_{o}^{2}\left[1-\left(\frac{r}{R}\right)^{2}\right]^{4} \operatorname{Exp}\left\{-8\left[1-\left(\frac{r}{R}\right)^{2}\right]\right\}
$$

Substituting and performing the indicated integration, the following expression is obtained

$$
\overline{\sigma^{2}}=1.93 \sigma_{o}^{2}
$$


for

$$
R_{e}=8510 \quad \sigma_{0}=2 \frac{\mathrm{cms}}{\mathrm{sec}}
$$

and

$$
\overline{\sigma^{2}}=7.72 \frac{\mathrm{cms}^{2}}{\mathrm{sec}^{2}}
$$

Since $f(v)$ is a normal distribution near the axis of the pipe representing a random distribution, the sampling period required to establish $f(v)$ is equal to the time required for invariance ( $T$ ). At the Reynold's number under consideration, this was found to be approximately twenty seconds. This time was determined by sampling through increasingly larger periods of time and plotting $f(v)$ for each sampling period. The sampling time required for the normalized velocity distribution function $(f(v))$ to remain unchanged by increasing the sampling time was determined.

A set of distribution functions so determined are shown in Figure 15. These functions are not normalized so that the last two curves will not fall on top of one another. However, it can be seen that $T \cong 20$ secs.

Substituting into equation (13), yields

$$
\mathrm{D}=77.2 \frac{\mathrm{cms}^{2}}{\mathrm{sec}}
$$

Eddy diffusivity was determined for the corresponding value of Reynold's number using turbulent mixing data and was found to be 89 $\mathrm{cms}^{2}$ /sec. Therefore, agreement was obtained within the author's ability to determine $\mathrm{T}$ and $\mathrm{D}$ experimentally.

When $T$ is small, $v(t+T) v(t) \cong v^{2}(t)$; that is, the correlation coefficient is approximately unity. In this case a tracer will diffuse to produce a distribution function of the same for $m$ as the velocity distribution function.

Experiments were devised to measure the concentration of a salt tracer downstream from the point of injection. A pulse of salt tracer with a time interval of less than 0.1 second was introduced at $X=0$, and the conductivity was measured as a function of time at different values of $X$ (distance downstream). Figure 16 is an illustration of the results of one such run. As indicated in Figure 16, the data more closely approximates a normal distribution than the distribution calculated from the eddy 
diffusion model. Since the point of measurement is close to the source and the eddy diffusion model does not produce the same shape of curve as the data, it may be surmised that the distance downstream from the source is sufficiently small that the measured distribution is more closely associated with the distribution of the velocity of fluctuation. Therefore, the fact that the data shown in Figure 16 approximates a normal distribution indicates that the velocity distribution function that produced the diffusion was normal. This is, of course, compatible with the correlated velocity distribution functions. If the concentration gradient is measured at a point sufficiently distant from the source, the eddy diffusion model will apply regardless of the form of the velocity distribution function and will not be indicative of the latter. 


\section{CONCLUSIONS}

The measured velocity distribution function is verified for both its mean value and the variance. The mean velocities were verified with existing data by Nikuradse, and a profile in radius of the mean values is shown.

The shape of the measured distribution function agreed with concentration gradients measured near the source. The measured variances were verified by calculating the corresponding eddy diffusivities and comparing them with the measured eddy diffusivities.

The general velocity distribution function was established with data and a statistical derivation. The general velocity distribution function accounts for the increase in skewness in the distribution function that appears as the radius approaches the pipe wall. The authors do not feel that sufficient data is yet a vailable near the wall to completely confirm the general velocity distribution function; however, the existing data shows good agreement. Further, the velocity distribution, as measured near the center of the pipe, is a normal distribution that is in agreement with the derived general velocity distribution function.

It was established that the distribution function and the variation in radius agreed with accepted statistical concepts.

It is possible, as shown in this report, to derive the function describing the variation of the variance as a function of radius using accepted statistical concepts of fluid mechanics. This function is verified by the data obtained. 


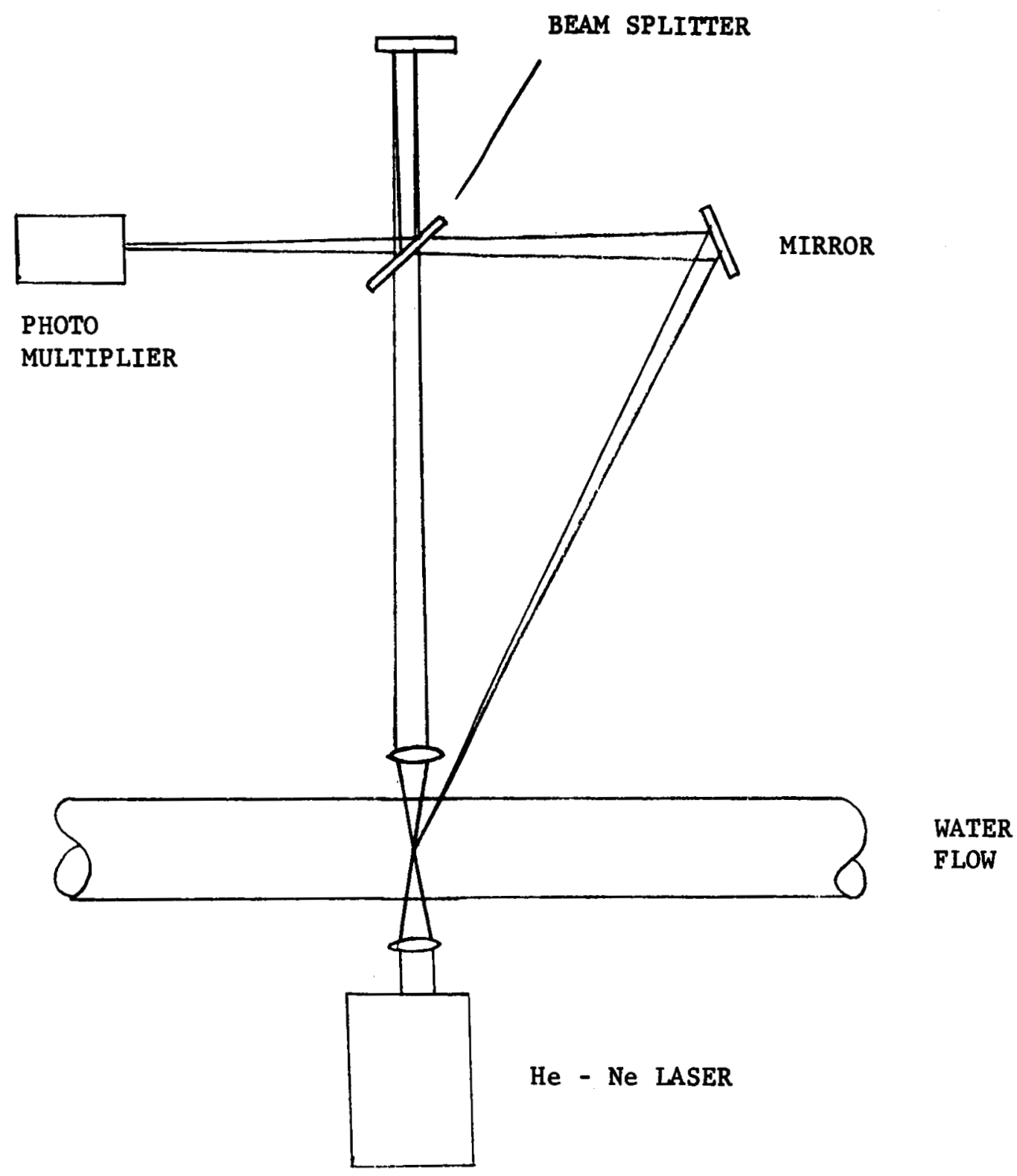

FIGURE 1 - OPTICAL SYSTEM 


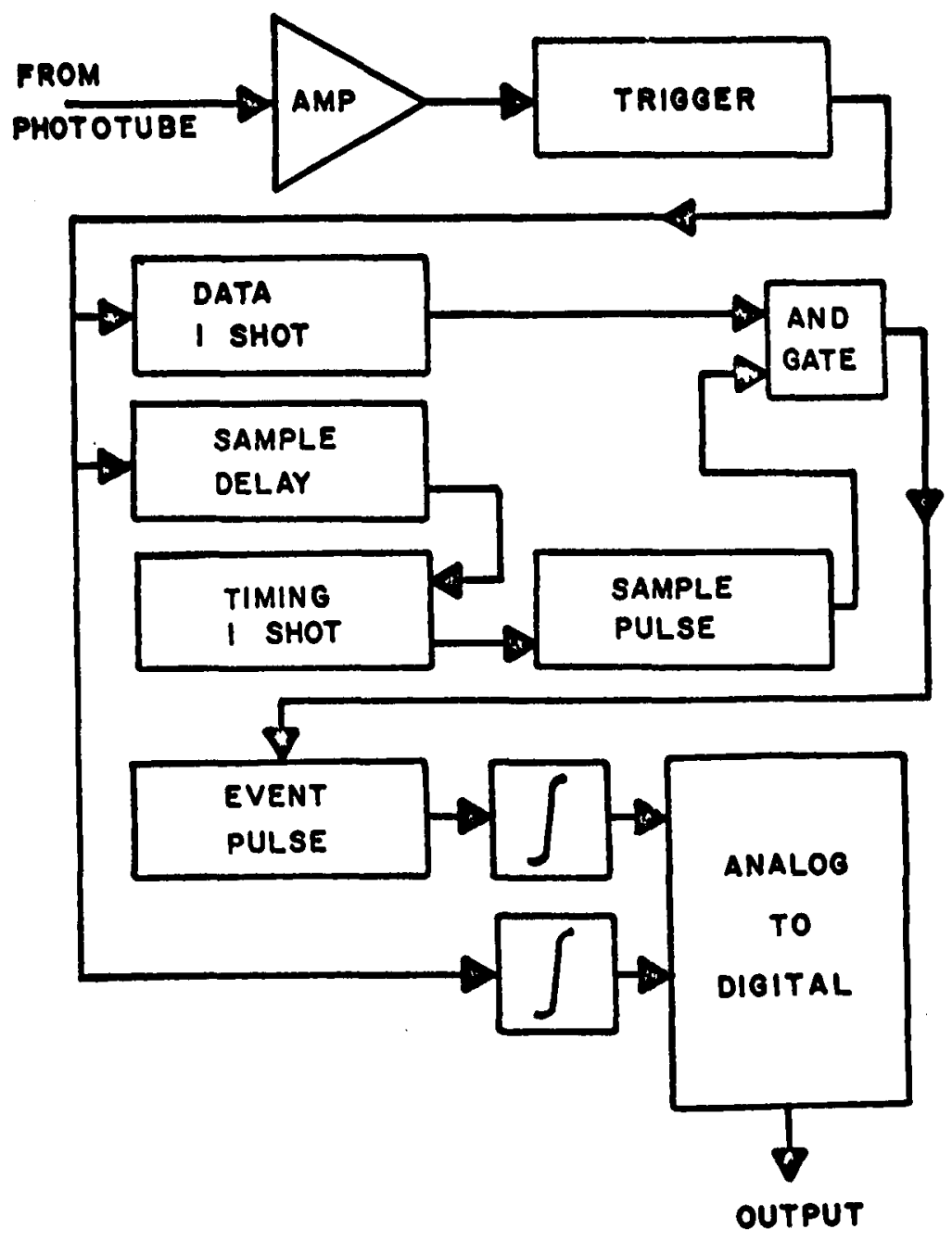

FIGURE 2 - ELECTRONIC SYSTEM 


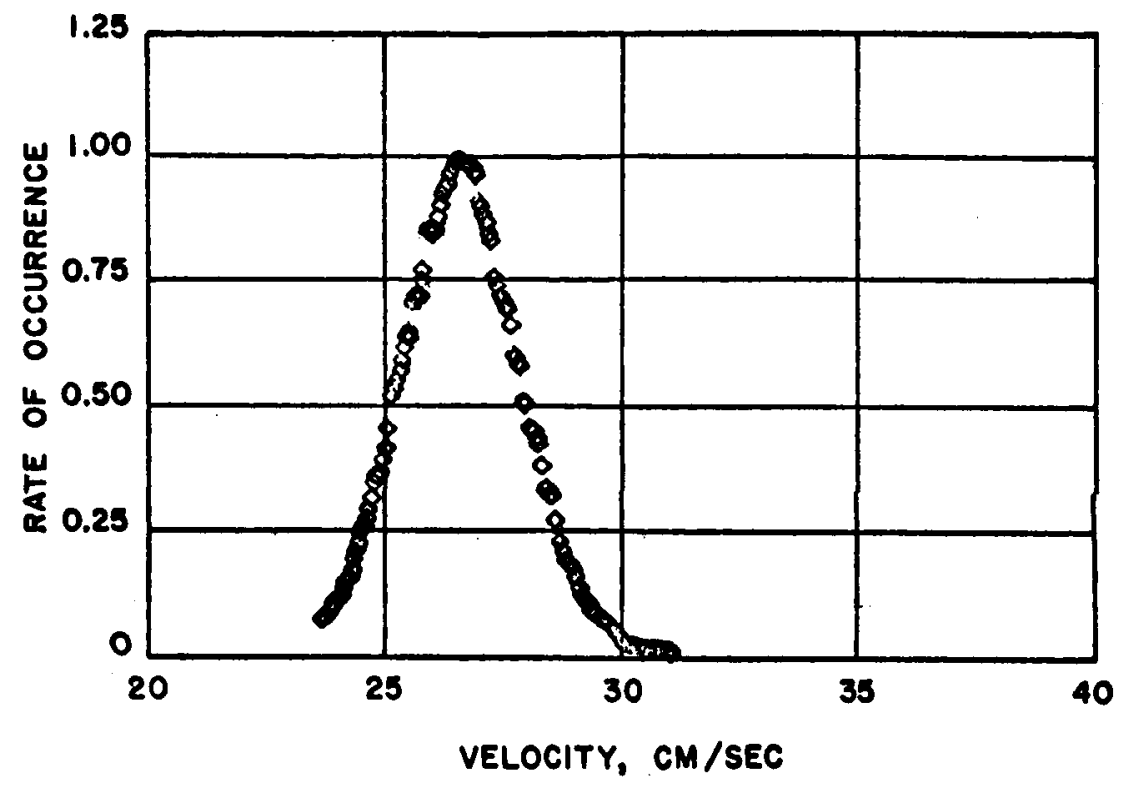

FIGURE 3 - CENTER LINE VELOCITY DISTRIBUTION FOR A REYNOLDS NUMBER OF 4605

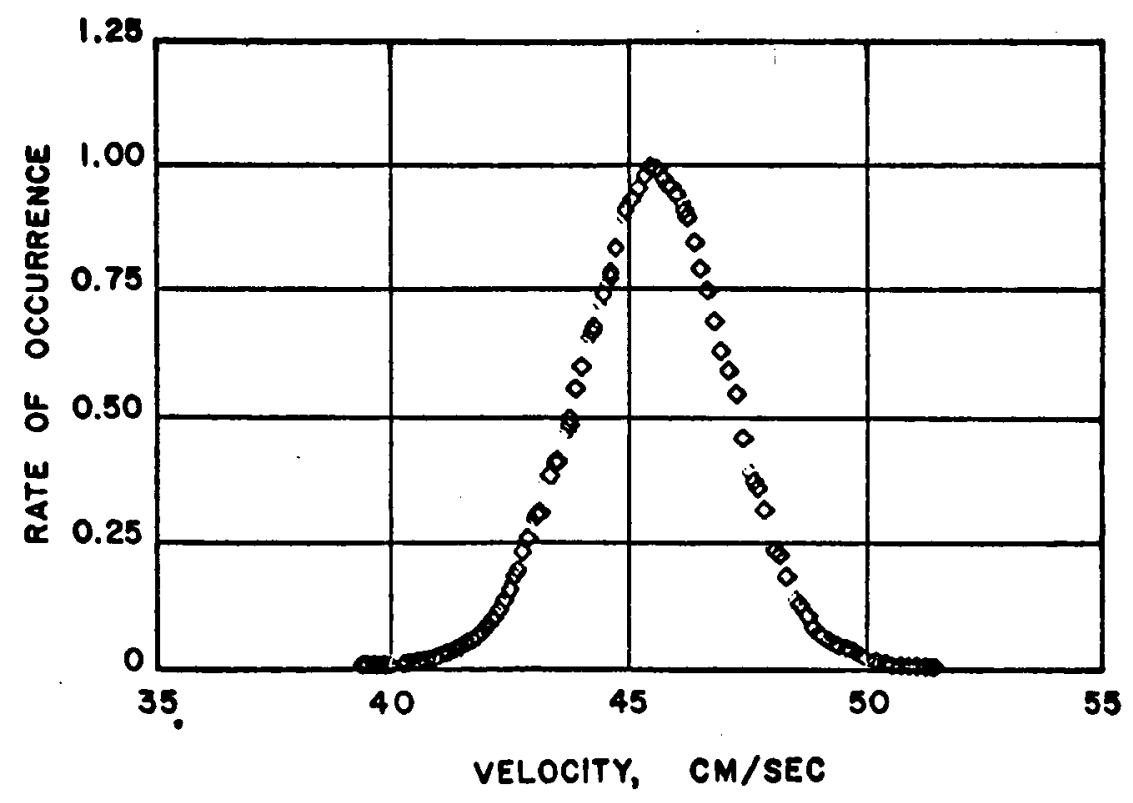

FIGURE 4 - CENTER LINE VELOCITY DISTRIBUTION FOR A REYNOLDS NUMBER OF 7808 


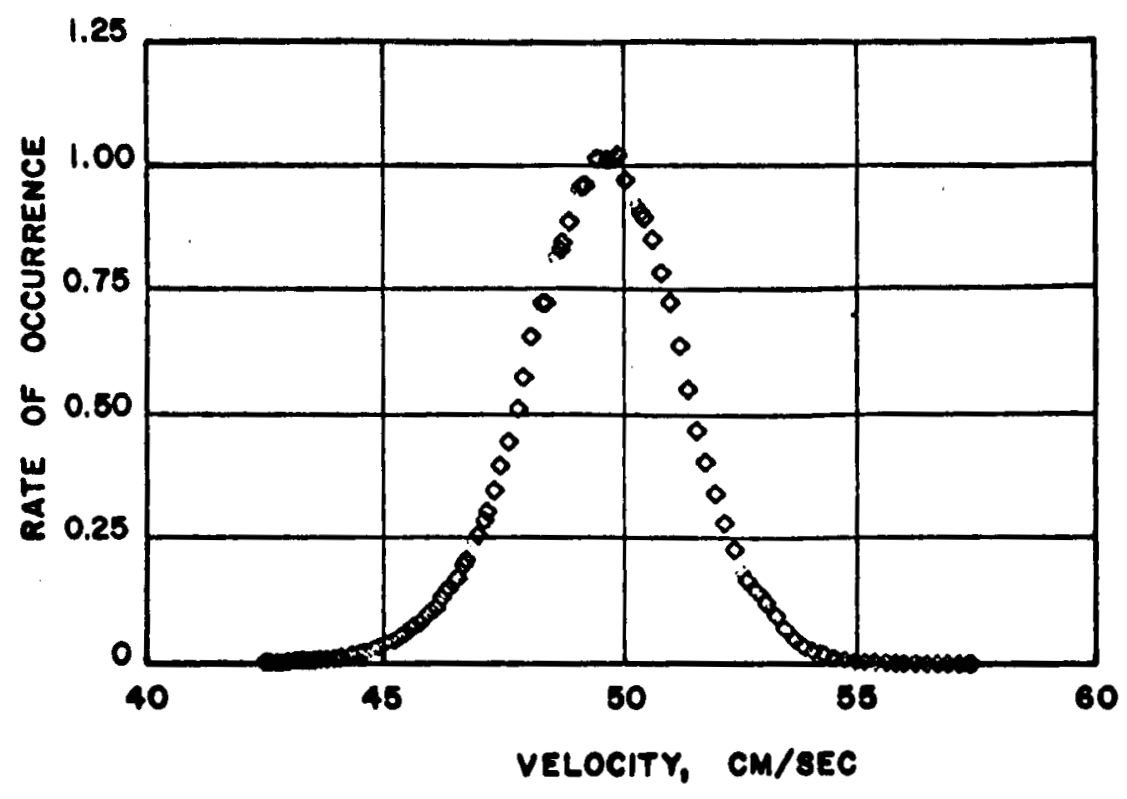

FIGURE 5 - CENTERLINE VELOCITY DISTRIBUTION FOR A REYNOLDS NUMBER OF 8510

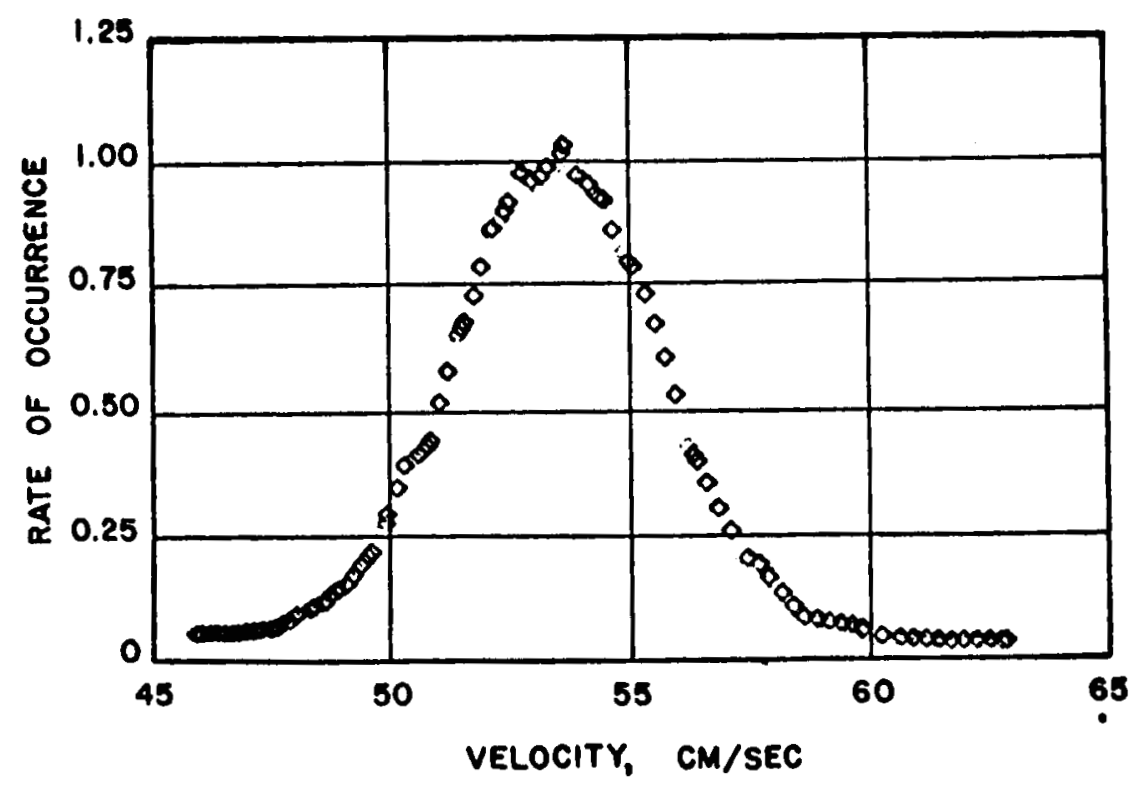

FIGURE 6 - CENTER LINE VELOCITY DISTRIBUTION FOR A REYNOLDS NUMBER OF 9310 


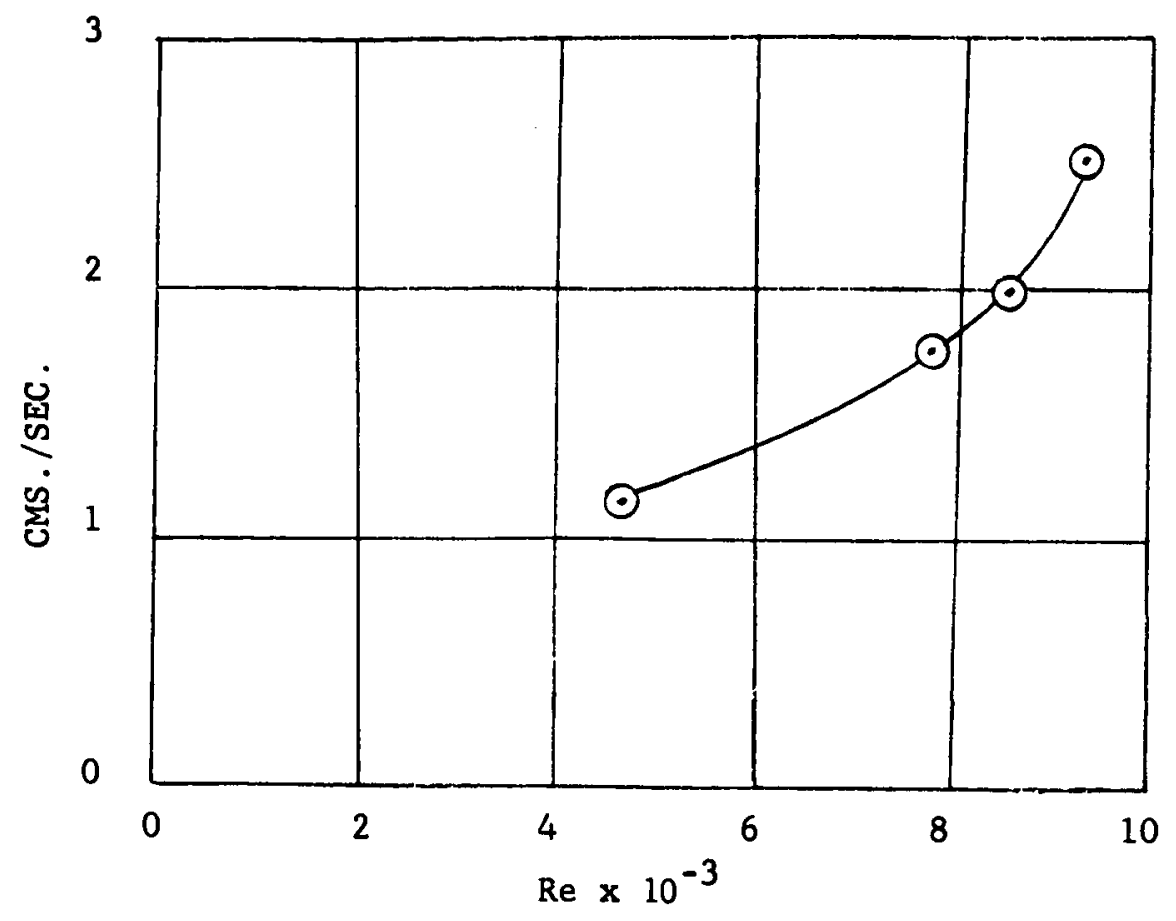

FIGURE 7 - STANDARD DEVIATION FOR VARIOUS REYNOLDS NUMBERS

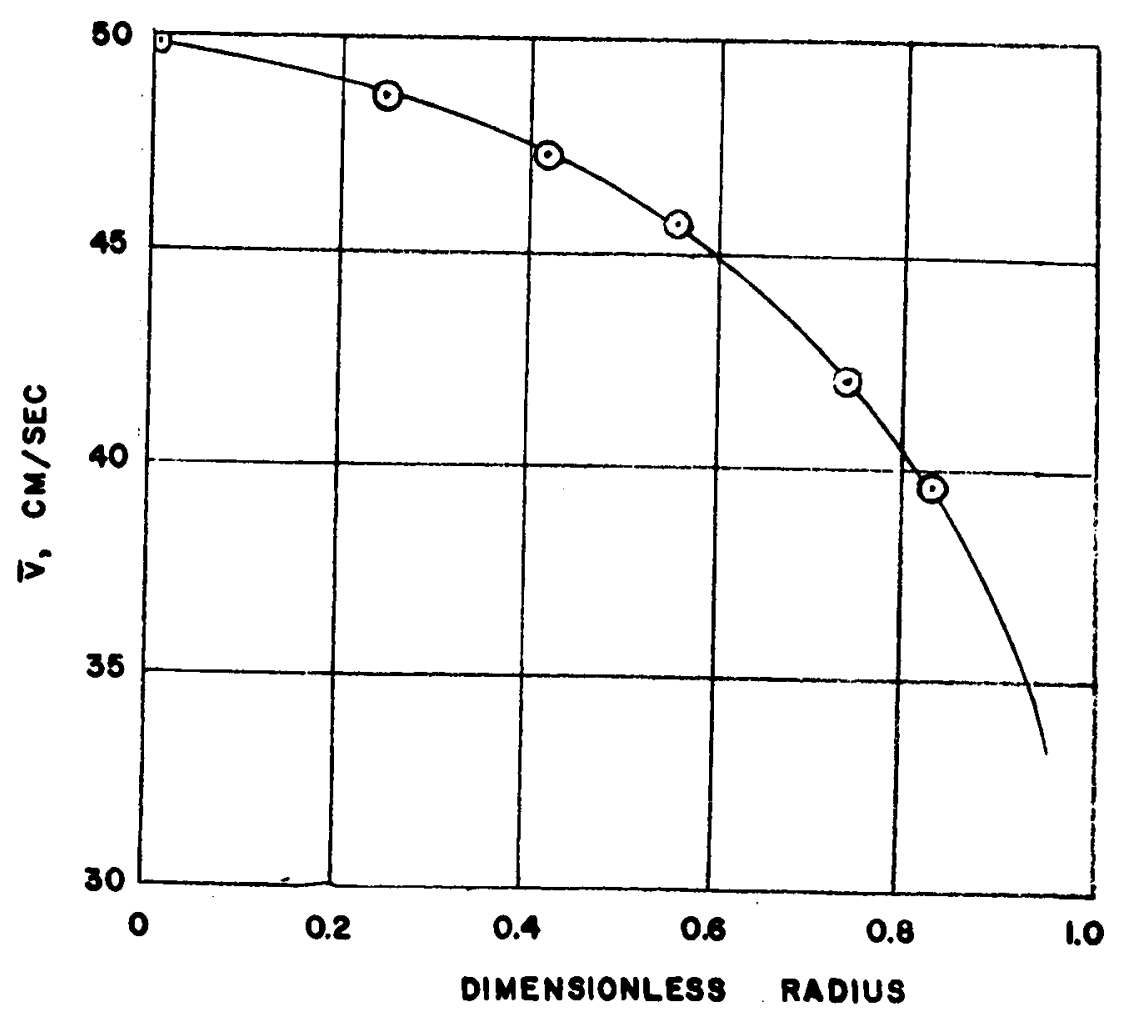

FIGURE 8 - PROFILE OF MEAN VELOCITY AT A REYNOLDS NUMBER OF 8510 


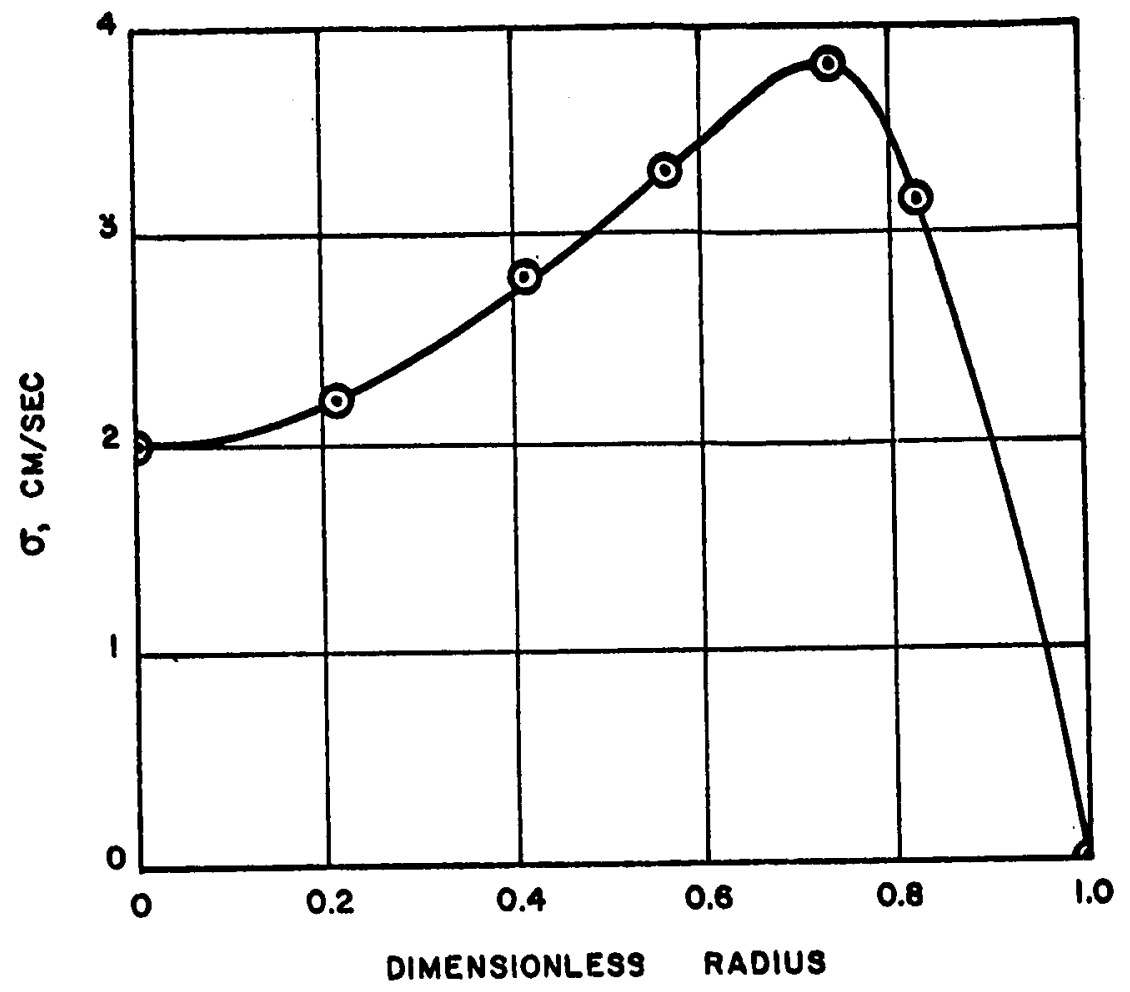

FIGURE 9 - STANDARD DEVIATION AT SEVERAL RADII FOR REYNOLDS NUMBER OF 8510 


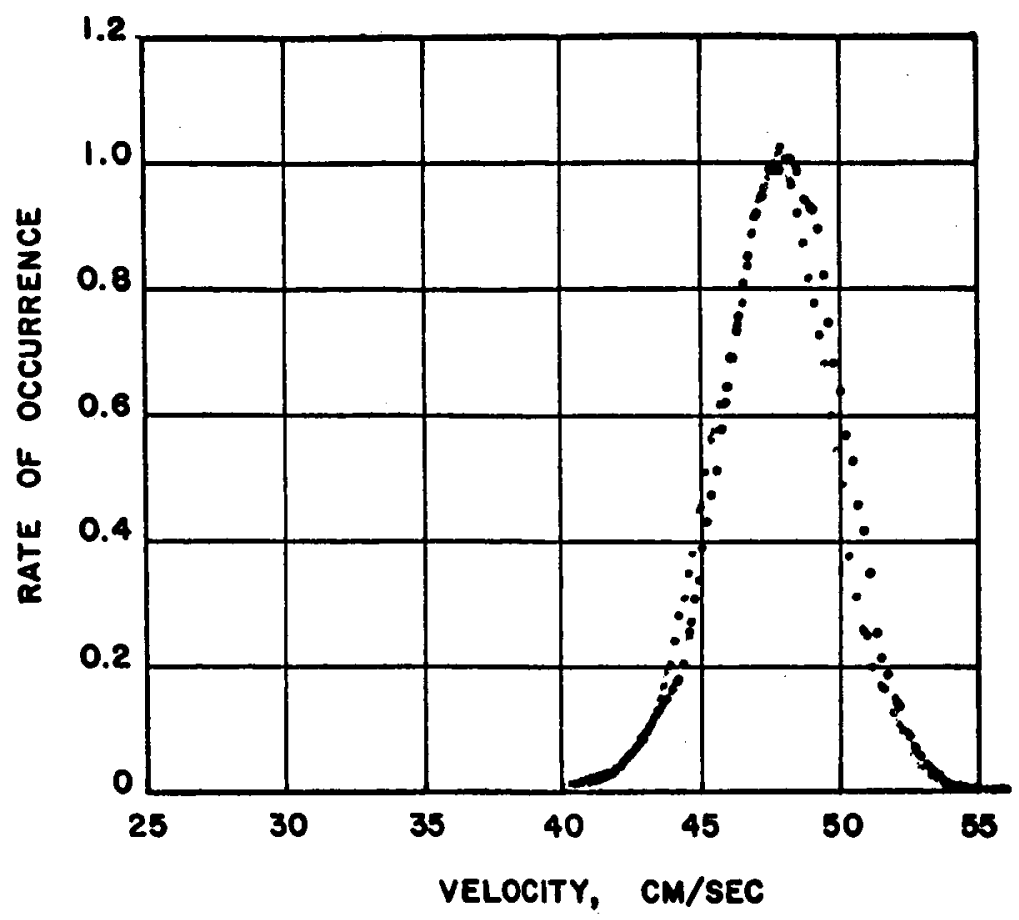

FIGURE 10 - VELOCITY DISTRIBUTION AT AN r/R OF 0.243 AND A REYNOLDS NUMBER OF 8510

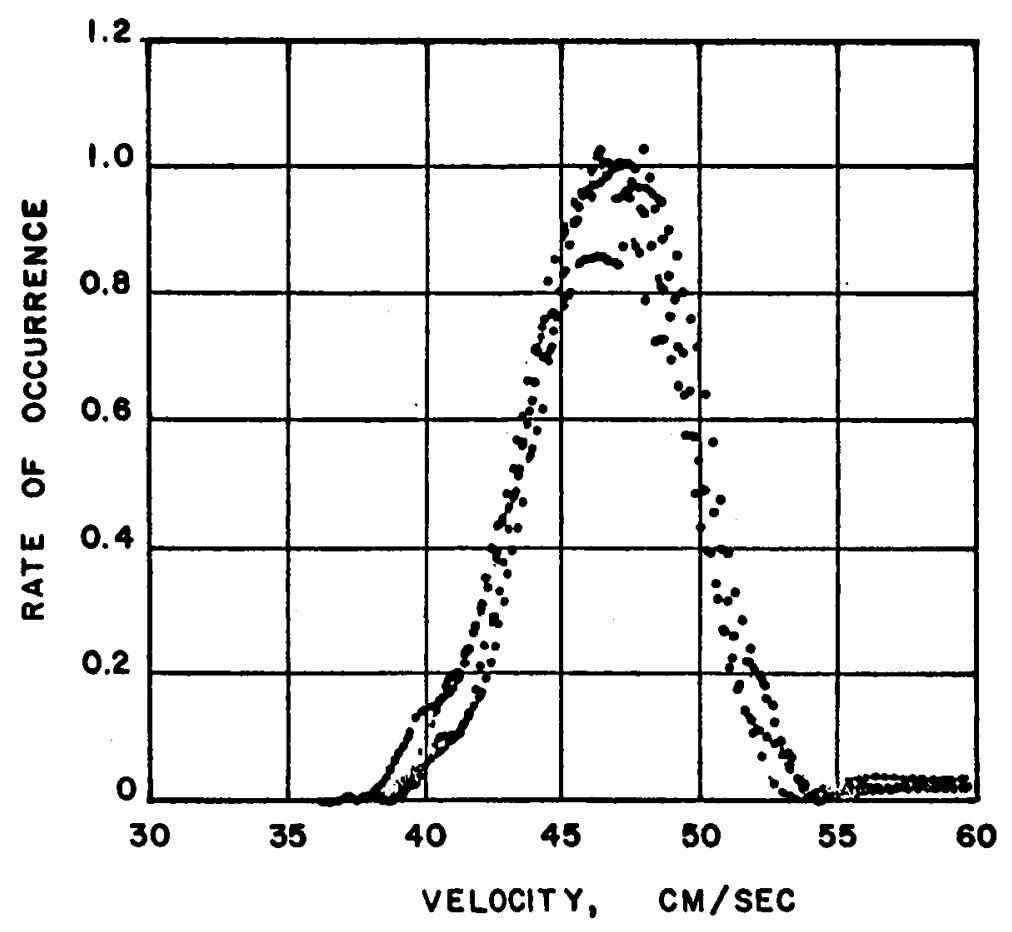

FIGURE 11 - VELOCITY DISTRIBUTION AT AN r/R OF 0.405 AND A REYNOLDS NUMBER OF 8510 


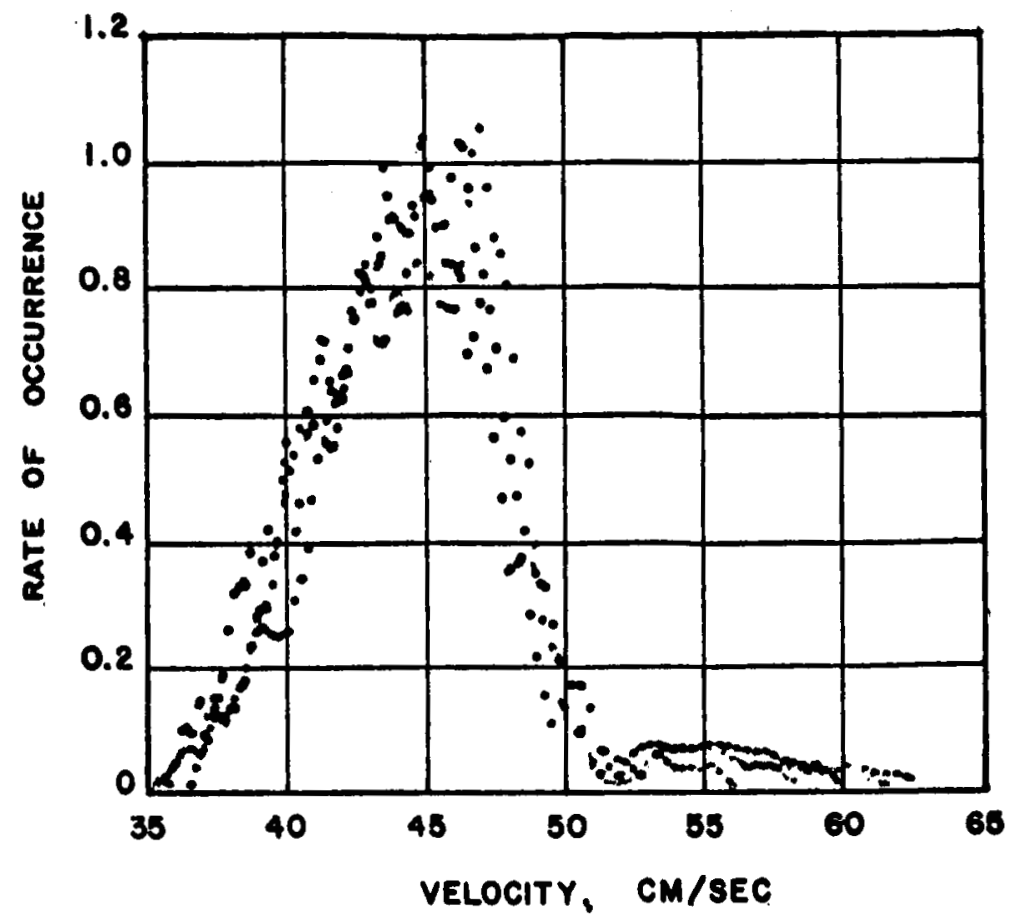

FIGURE 12 - VELOCITY DISTRIBUTION AT AN r/R OF 0.566 AND A REYNOLDS NUMBER OF 8510

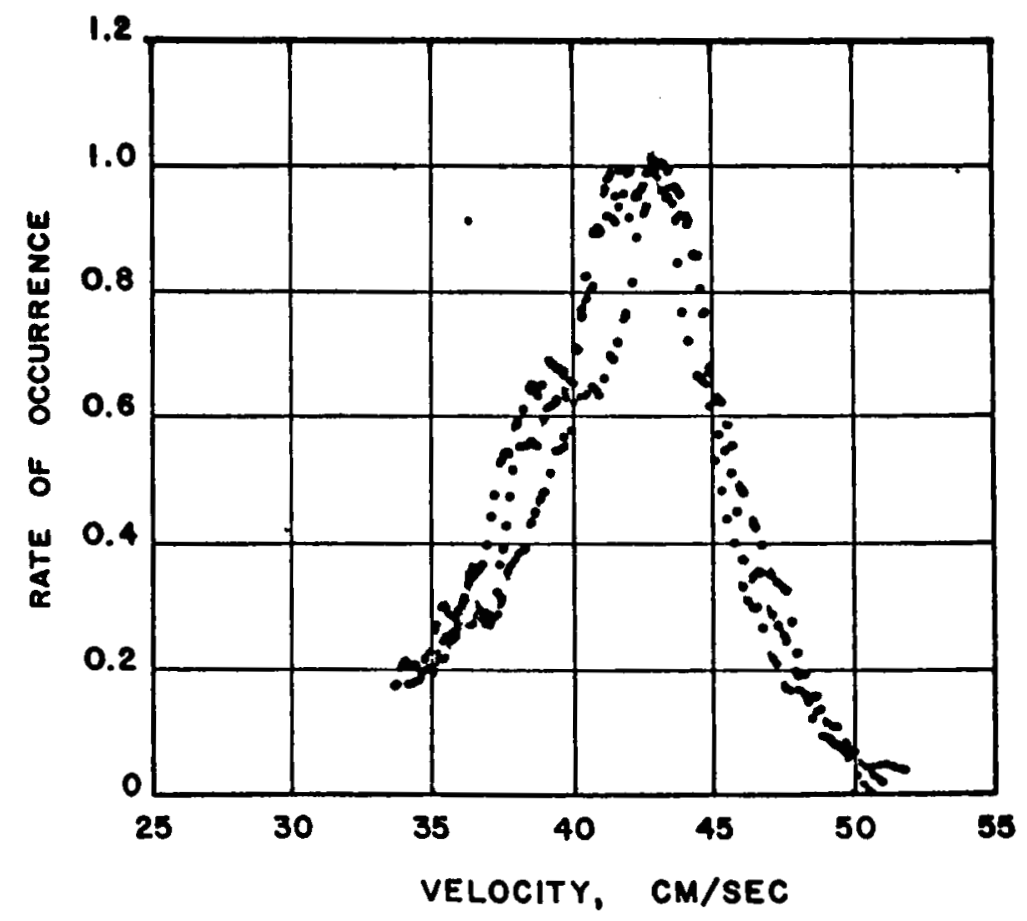

FIGURE 13 - VELOCITY DISTRIBUTION AT AN $x / R$ OF 0.729 AND A REYNOLDS NUMBER OF 8510 


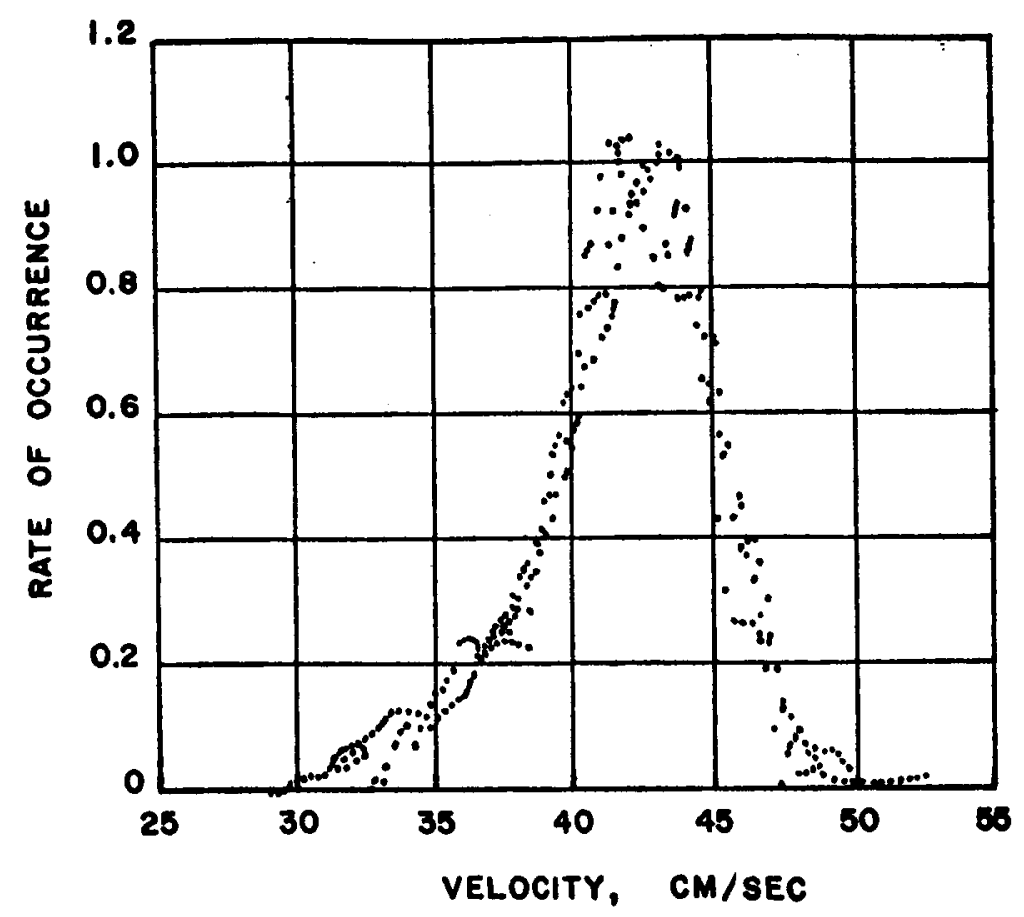

FIGURE 14 - VELOCITY DISTRIBUTION AT AN r/R OF 0.825 AND A REYNOLDS NUMBER OF 8510

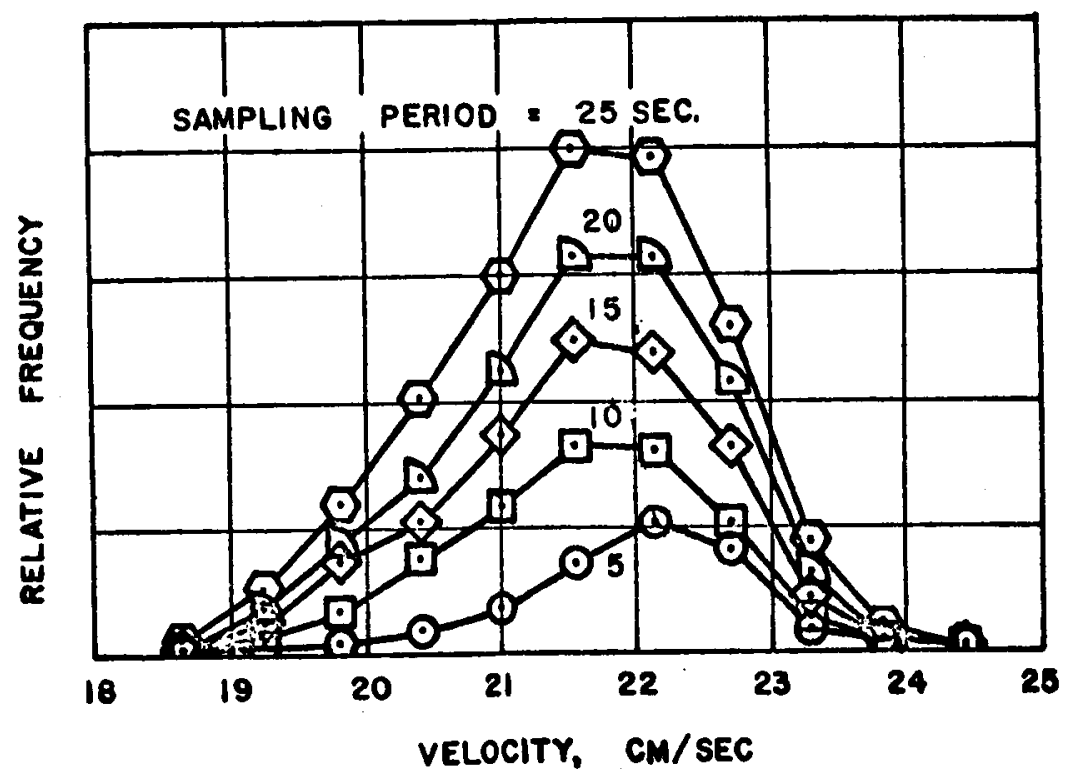

FIGURE 15 - EFFECT OF SAMPLING PERIOD 


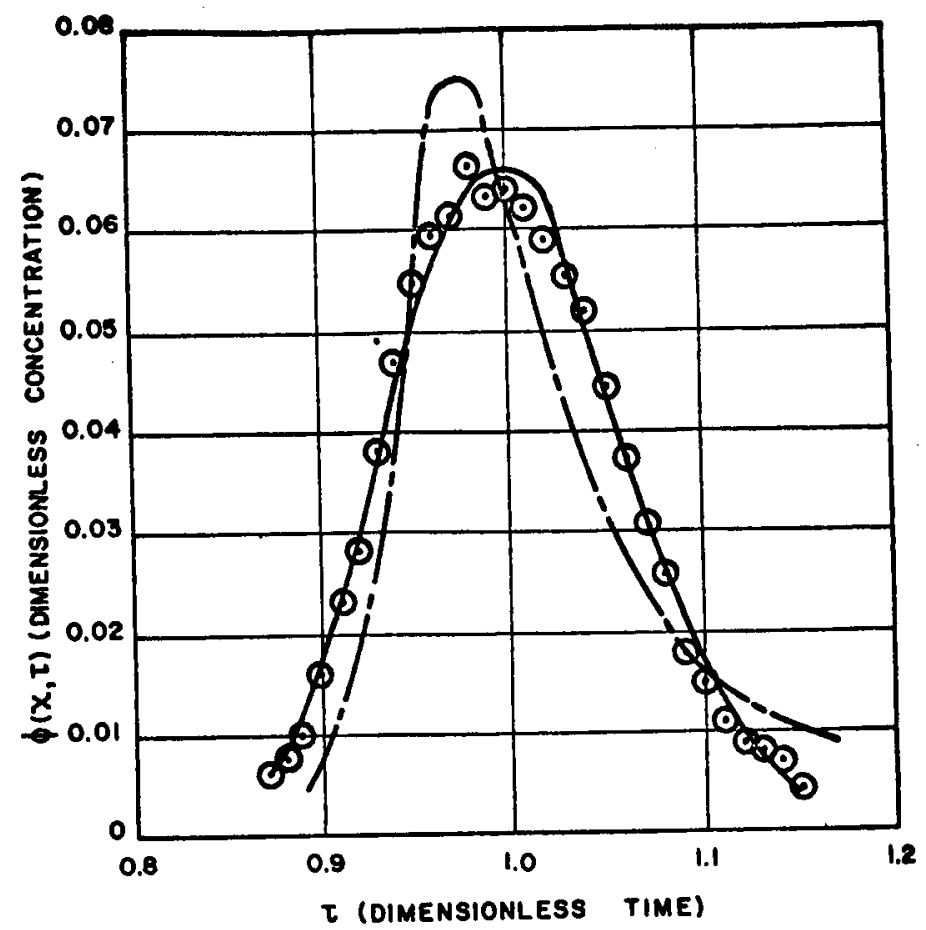

O CONCENTRATION DATA

- EDOY DIFFUSION MOOEL

FIGURE 16 - DIFFUSION CHARACTERISTIC OF TURBULENT FIELD

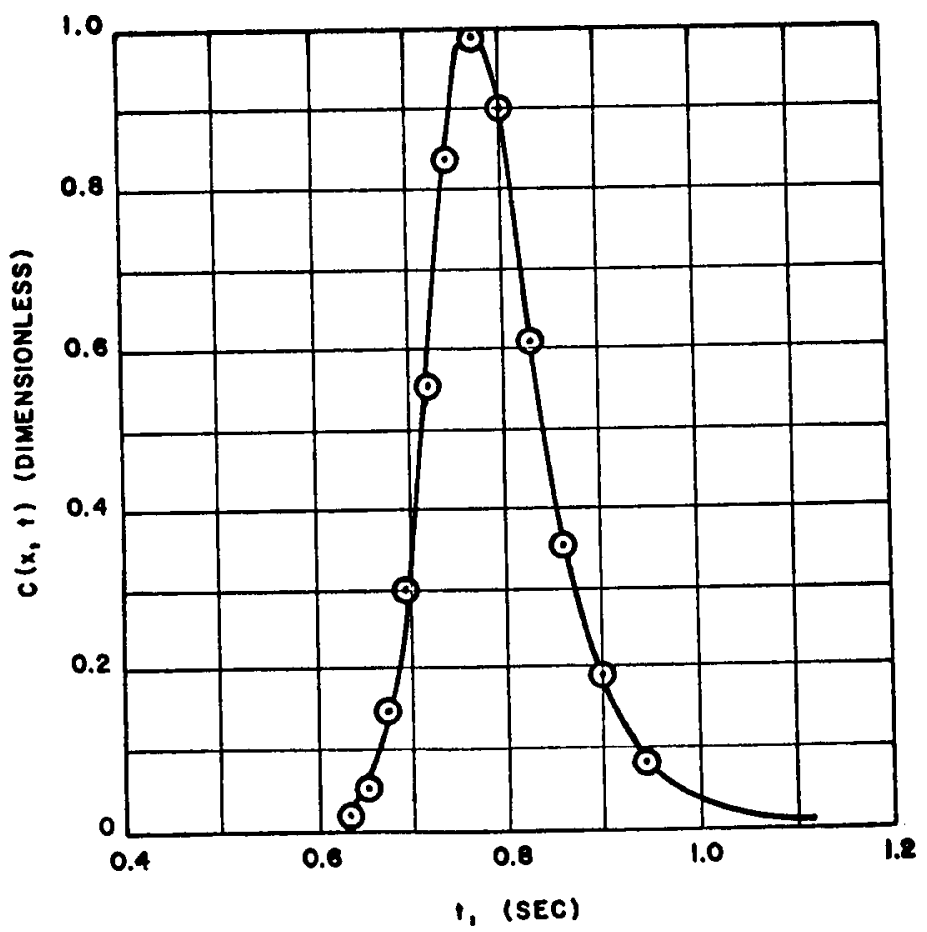

FIGURE 17 - CONCENTRATION GRADIENT CALCULATED FROM VELOCITY DISTRIBUTION FUNCTION 
TABLE I

AVERAGE VALUES FOR VARIANCE

AND VELOCITY AT CENTERLINE

\begin{tabular}{|c|c|c|c|c|}
\hline $\begin{array}{c}\text { RUN } \\
\text { SERIES }\end{array}$ & $\operatorname{Re}$ & $\bar{\sigma}^{2}$ & $\bar{v}$ & $V$ \\
\hline 4 & 4605 & 1.33 & 26.86 & 20.93 \\
\hline 5 & 7808 & 2.97 & 45.82 & 35.49 \\
\hline 8 & 8510 & 3.98 & 50.25 & 38.68 \\
\hline 9 & 9310 & 6.23 & 54.02 & 42.32 \\
\hline 10 & 8510 & 3.89 & 49.84 & 38.68 \\
\hline
\end{tabular}


1. Foreman, J.; Lewis, R., and George, E.: Measurement of Localized Flow Velocities in Gases with a Laser Flowmeter. Applied Physics Letter s, Vol. 7, No. 4, August 15, 1965.

2. Nikuradse, J.: Stromungsgesetze in rauhen Rohren. For schg. -Arb. Ing. - Wesen No. 361 (1933).

3. Foreman, J.; George, E.; Jetton, J; Lewis, R.; Thornton, J.; and Watson, H.: Fluid Flow Measurements with a Laser Doppler Velocimeter. Vol. QE-2, No. 8, August 1966.

4. Welch, N. E. ; and Tomme, W. J.: The Analysis of Turbulence From Data Obtained with a Laser Velocimeter. AIAA 5th Aerospace Sciences Meeting, New York, New York, January 23-26, 1967. 
February 5, 1968

THE ANALYSIS OF TURBULENCE FROM DATA

OBTAINED WITH A LASER VELOCIMETER

By N. E. Welch and W. J. Tomme

The information in this report has been reviewed for security classification. Review of any information concerning Department of Defense or Atomic Energy Commission programs has been made by the MSFC Security Classification Officer. This report, in its entirety, has been determined to be unclassified.

This document has also been reviewed and approved for technical accuracy.

11. E. Welch

N. E. WELCH

Chief, Research Analysis Section

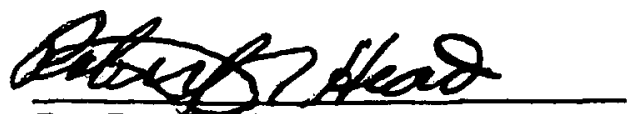

R. R. HEAD

Chief, Applied Research Branch

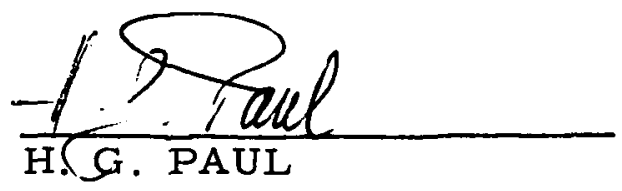

Chief, Propulsion Division

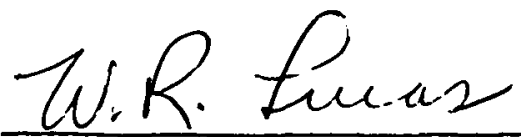

W. R. LUCAS

Director, Propulsion and Vehicle Engineering Laboratory 


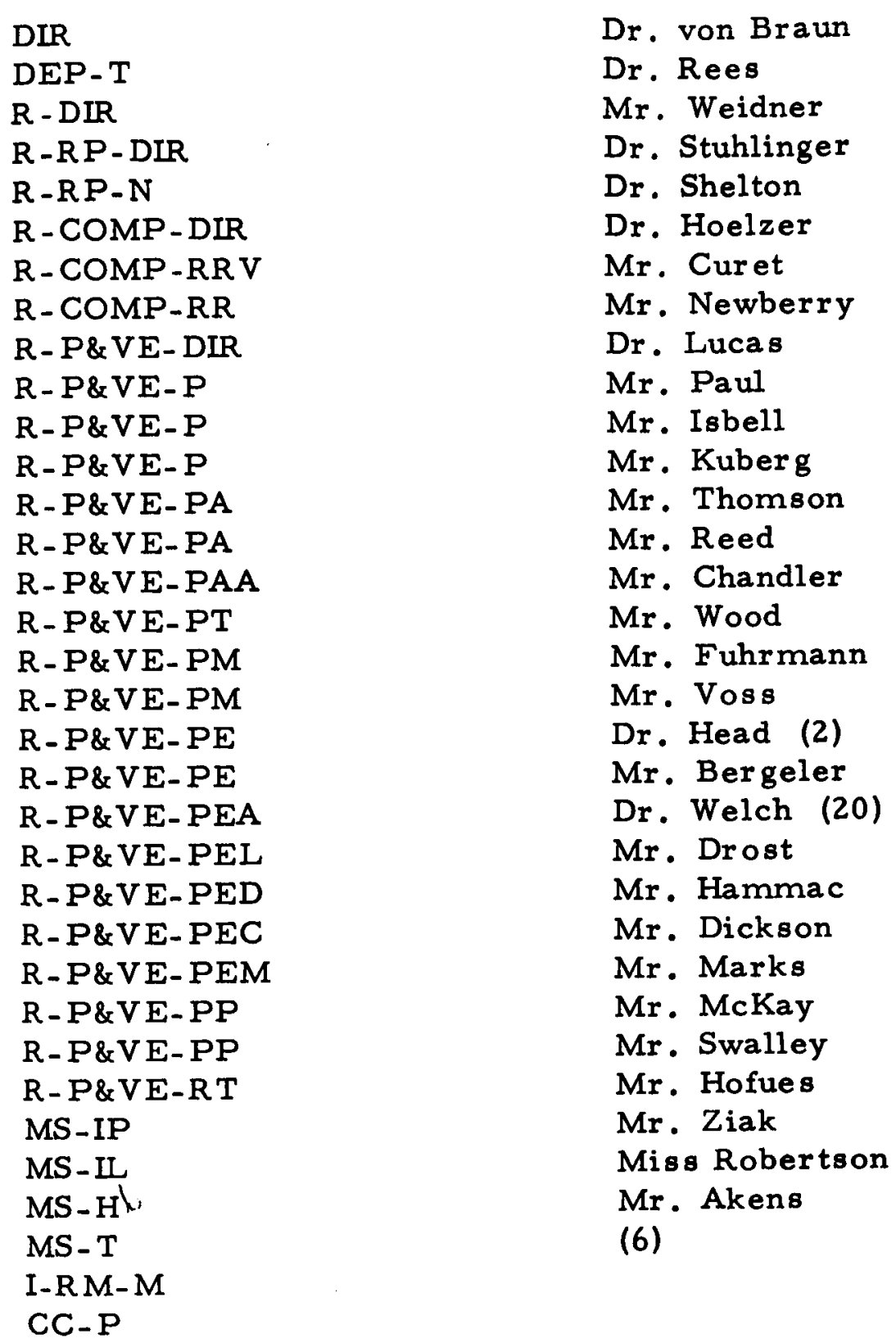

Dr. von Braun

Dr. Rees

Mr. Weidner

Dr. Stuhlinger

Dr. Shelton

Dr. Hoelzer

Mr. Curet

Mr. Newberry

Dr. Lucas

Mr. Paul

Mr. Isbell

Mr. Kuberg

Mr. Thomson

Mr. Reed

Mr. Chandler

Mr. Wood

Mr. Fuhrmann

Mr. Voss

Dr. Head (2)

Mr. Bergeler

Dr. Welch (20)

Mr. Drost

Mr. Hammac

Mr. Dickson

Mr. Marks

Mr. McKay

Mr. Swalley

Mr. Hofues

Mr. Ziak

Miss Robertson

Mr. Akens

(6)

Scientific and Technical Information Facility

Attn: NASA Representative (S-AK/RKT)

P. O. Box 33

College Park, Maryland 20740 